\title{
Assessment of Knowledge and Practice Toward Oral Hygiene Among Pregnant Women Attending Antenatal Care at Shashamane Referral Hospital, Oromia Region, Ethiopia 2019
}

\author{
Kababa Temesgen* keneni Berhanu Gurmesa Daba Fikadu wondimu \\ Department of Midwifery, College of Medicine and Health Sciences, Ambo University, Ambo, Ethiopia
}

\begin{abstract}
Background:- A woman's health needs are unique. It is known that at specific times in her life times when she matures and changes, for example, at times when she has special health needs such as menstruation or pregnancy; she needs to take extra care of herself. At the time of pregnancy, women are more susceptible to oral health problems and hence should to take extra care. The first step for a public health intervention program that targets engaging pregnant women in keeping their oral health care should be assessing the women's knowledge, attitude and practice. Objective:-To assess the magnitude of Knowledge and Practice of pregnant women towards their oral health care attending Shashamane Referral Hospital 2019.Method:-A prevalence cross-sectional descriptive study was conducted from April1-May30 at SRH, Oromia Region, Central Ethiopia. The data was collected by structured questionnaire through face to face interviewing technique. During the study period, pregnant women who attend for Ante Natal Care was included in the sample by systematic random sampling method. Result:- Total of 422 pregnant women were interviewed giving $100 \%$ response rate. About $110(26 \%)$ of the respondents reported bleeding gum during pregnancy. The result also showed that $146(34.6 \%)$ and $129(29.4 \%)$ of respondents labeled as having satisfactory knowledge and safe practice towards their oral health care, respectively. Conclusion and recommendation:- Most of pregnant women had unsatisfactory knowledge and unsafe practice towards oral health care.
\end{abstract}

Keywords: knowledge, practice, oral hygiene, antenatal care

DOI: $10.7176 / \mathrm{JHMN} / 66-06$

Publication date:September $30^{\text {th }} 2019$

\section{Introduction}

Pregnancy is a natural process which may create some changes in different parts of body including oral cavity. Changes in the oral cavity, during pregnancy are believed to be related to fluctuations in the level of estrogen and progesterone leading to an increase in oral vascular permeability and a decrease in host-immune competence, thereby increasing the susceptibility to oral infections (1).

A woman's health needs are unique. It is known that at specific Period in her life times when she matures and changes, for example, at puberty or menopause, and times when she has special health needs such as menstruation or pregnancy, she needs to take extra care of herself. Oral health care which includes the health care of the teeth, the gums and the mouth is one of the unique health needs at specific times in woman's life. While women tend to take better care of their oral health than men do women's oral health is not markedly better than men's. This is because of hormonal fluctuations throughout woman's life span (2).

Women may experience increased gingivitis or pregnancy gingivitis beginning in the second or third month of pregnancy that increases in severity throughout the eighth month. During this time, some women may notice swelling, bleeding or tenderness in the gum tissue (3).

The pregnancy gingivitis is more common in the front of mouth. The symptoms of pregnancy gingivitis are the same as that of gingivitis, but some of the causes of pregnancy gingivitis are different. Increased hormone levels may be partly responsible for pregnancy gingivitis. Also the immune system may work differently during pregnancy. This could change the way the body reacts to the bacteria that cause gingivitis (4).

The other problem during pregnancy that can affect the oral health is what is normally called morning sickness. It is typically seen in the first trimester. In women with severe and prolonged morning sickness, frequent vomiting can erode the enamel on the back of the front teeth. Frequent vomiting can leave stomach acids in the mouth. If these acids are not cleared away quickly, could damage surfaces of teeth and cause tooth decay. Less commonly, pregnant women feel they have too much saliva in their mouth. This condition occurs very early in pregnancy. It disappears by the end the first trimesters. It may be associated with nausea. But, many other women complain of dry mouth (4).

The aims of dental health care in pregnancy are: firstly, to establish a healthy environment through adequate plaque control and diet to expectant mothers; secondly, to provide information to pregnant women about the link between dental health and birth outcomes with the intention of providing sufficient knowledge to assist women to make healthy choices and; finally, to improve access to dental health care for all women. This has the potential to lead to better oral health outcomes, not only for the women themselves, but also for their families since caregivers 
are responsible for introducing good habits to their children, including eating a healthy diet and maintaining a sound level of oral hygiene. According to the Ministry of Health in newzeland, high levels of dental caries in childhood predict greater oral health disease levels in adulthood, even when other factors, such as hygiene and diet are taken into account. In addition, research has also shown that periodontal disease in pregnant women can affect pregnancy outcomes (5).

\section{OBJECTIVES}

\section{General Objective}

To assess the magnitude of Knowledge and Practice toward oral hygiene among pregnant women at SRH in ANC follows -up, Oromia region, Ethiopia 2019.

\section{Specific Objective}

To assess the magnitude of Knowledge of pregnant women towards oral health care in SRH,Oromia region, Ethiopia 2019.

To assess the magnitude of safety oral health care Practices of pregnant women in SRH, Oromia region, Ethiopia 2019.

\section{METHODS AND MATERIALS}

\section{Study Area}

The study was conducted at ANC clinic which is found in Kuyera town,,WesternArisi, Oromia region, South East Ethiopia. It is found $240 \mathrm{~km}$ away from Addis Ababa. The town has a total population of 4,534; out of which 2,358 were female with a total household of 1,089 . The weather condition of the town is woinadega. The hospital provides the following services: Internal medicine, Surgery,Orthopedics, Obstetrics and Gynecology, Pediatrics, Radiology, Pharmacy, Clinical laboratory, Nursing and Midwifery Services.

\section{Study Design and Study Period}

A descriptive Cross-sectional study design was conducted and the study was carried out from April 1, to May 30 , 2019 .

Source population

All pregnant women came to SRH for ANC purpose.

Study population

Selected Pregnant women who were attended SRH for ANC during the data collection period.

\section{Inclusion and exclusion criteria}

\section{Inclusion criteria}

Pregnant women who were ANC follow up during the data collection period and volunteer to participate were included in the study.

\section{Exclusion criteria}

Pregnant women who were with high mental disorder and illness were excluded from the study.

\section{Sample Size}

Sample size was calculated using the formula for cross-sectional study for single proportion.

$\mathrm{n}=\underline{\mathrm{Z}^{2} \mathrm{p}(1-\mathrm{p})}$ where, $\mathrm{n}=$ sample size

$$
\begin{aligned}
& \mathrm{d}^{2} \quad \begin{array}{l}
\mathrm{Z}=\text { confidence interval }(1.96) \\
\mathrm{P}=\text { prevalence }(50 \%) \\
\mathrm{d}=\text { margin of sampling error to be tolerated }(0.05)
\end{array} \\
& \mathrm{n}=(1.96)^{2} \cdot 0.5(1-0.5)=384 \\
& (0.05)^{2}
\end{aligned}
$$

By adding non response rate $10 \%=384 \times 10 / 100=38.4$ so $38.4+384=422$

\section{Sampling technique}

The sampling technique that we were used is systematic random sampling method.The first was selected using lottery method and then every k- unit was selected based on the total population came to ANC visit last year with in the same time with our study period which was 900 so $\mathrm{k}=900 / 422=2$ so data was collected from each $2^{\text {nd }}$ interval

Study Variables:

Dependent variables; knowledge, practice

Independent variables: Age ,Religion ,Ethnicity,Educational status,Occupation ,Residency,Income,Smoking status,Marital status,Body Mass Index and Previous pregnancy

Operational definitions

Antenatal care: - The treatment and follow-up given for pregnant women before the delivery date. (16)

Good oral hygiene: - Teeth are found to have a very small amount of plaque, no calculus deposition, no discoloration or food debris found.(17)

Fair oral hygiene: - Teeth are found to have plaque, minimal amount of calculus with no discoloration or food 
debris. (17)

Poor oral hygiene: - Teeth are found to have plaque, heavy calculus deposition, discoloration or accumulation of food debris on most of teeth surfaces.(17)

Knowledge:- Familiarity, awareness or understanding gained through combination of data, information, experience and individual interpretation.(18)

Satisfactory knowledge:- If the respondent answers 50\% and more knowledge questions correctly.(26)

Unsatisfactory knowledge:- If the respondents answer less than 50\% of knowledge questions correctly.(26)

Practice:- To do something habitually or repeatedly.(19)

Safe practice:- If the respondents have no any risk practice according to their response to practice questions. (26) Unsafe practice:- If the respondents have at least one risk practice according to their response to practice questions. (26)

\section{Data collection Process}

The data for the study was collected by five data collectors who are Midwives after taking appropriate training. The data was collected by structured interview using a structured questionnaire. A standardized questionnaire which consisted of close ended questions was used to obtain desired information. The questionnaires were prepared in English and then translated in to Amharic and afan Oromo orally for the interviewee and then written by English.The questionnaire was designed with 30 questions to measure the Knowledge and Practices about oral hygiene among pregnant women, taking into account the respective social and cultural environment. The time of data collection was from April 1 to May 30, 2019. The instruments was used to collect the data contain three sections having a variable number of questions with multiple options in each section.

\section{Data presentation and Analysis}

The collected data was checked for its completeness, consistency and accuracy before analysis. It was processed and analysis by using descriptive statistics percentage, frequency, ratios, and the result was calculated by using scientific calculator during the analysis. The finding was presented by using pie chart and table.

\section{Data Quality control}

Information was collected from the respondents using face to face interview technique; data collection activity was started after approval by advisor. The questions prepared to cover necessary information which relates to the study (topic) and explanation was given to the importance of the study and the need to answer the question honestly for pregnant women who were attending ANC clinic in SRH. Before data collection pre-test was done in Melkaoda General Hospital using 5\% of population.

\section{Ethical Consideration}

A formal letter was written from Ambo University College of Health and medical sciences, Department of Midwifery to the SRH and verbal consent was asked from the respondents, privacy and confidentiality of the information was assured throughout the study procedure. The right of the respondents was told clearly. During data collection the purpose of the study was explained to each respondent and assured of confidentiality of any information they are giving.

\section{RESULT}

\section{Socio-demographic characteristics}

The total of 422 pregnant women was sampled to be interviewed and 422 were involved giving $100 \%$ response rate.

The study revealed that majority of respondents 242(57.3\%) were found in the age group of 20-24 years followed by $116(27.5 \%)$ and which were found in the age group of 25-29 years. Most of them 373(88.4\%) were married and 44(10.4\%) were single. With regard to religion, 115(27.2\%) were Orthodox,192(45.4) Muslim and 103(24.3\%) were Protestant. Majority of the respondents were house wife, and 106(25.1\%) of them were merchant. Regarding residence, majority of them 173(40.9\%) live in rural. Regarding Education 123(29.2\%) of the respondents have attended secondary school. With regard to income, 197(46.8\%) of the respondents had a monthly income of $(500-$ 1000) birr.

\section{Knowledge of the respondents towards their oral health care}

Assessment of the basic knowledge of respondents towards their oral health care revealed that $162(38.3 \%) \mathrm{knew}$ that not keeping oral hygiene could lead to gum and tooth disease; 171(40.6\%) knew that gum and tooth diseases could result in bad oral breath (halitosis). About 133(31.5\%) of them knew that gum diseases could result in red, swollen gums that can bleed easily and $188(44.5 \%)$ of them knew that tooth cleaning is more necessary during pregnancy, and $138(32.8 \%)$ of them know gum diseases could be treated with careful brushing and flossing at home. The $279(66.1 \%)$ did not know even the means and duration of tooth cleaning. Although, 140(33.1\%) of them knew that pregnant mothers might be susceptible to gingivitis, 369(87.5\%) did not know that gingivitis during pregnancy might lead to LBW and PTB.

Overall, assessment of the knowledge of the respondents regarding their oral health care, the study revealed that $146(34.6 \%)$ of respondents labeled as having 'satisfactory knowledge' while the rest $276(65.4 \%)$ of them as 
having 'Unsatisfactory knowledge.

Practice of pregnant women's towards their oral health care

The result of study revealed that out of a total of 422 respondents, the 341(80.7\%) of them had not visited dental practitioner at all during their pregnancy (table4). All of the respondents had a habit of tooth brushing but only 81 $(19.3 \%)$ of them had a habit of flossing their tooth (table4). Out of the $422(100 \%)$ of respondents who had a habit of tooth brushing, 319(75.5\%) of them use traditional stick (Mefakia) to brush their tooth, 103(24.5\%) use tooth brush with tooth paste. Regarding frequency of tooth brushing, 316(74.9\%) of those having the habit of tooth brushing, have brushed their tooth irregularly and 51(12\%) of them have brushed their tooth twice a day.

Overall, assessment of the practice of the respondents regarding their oral health care, the study revealed that $124(29.4 \%)$ of the respondents had "safe practice" while the rest 298(70.6\%) had "unsafe practice" towards their oral health care.

Table 4:-Dental visit practice, Tooth cleaning practice and material used for tooth cleaning practiceduring pregnancy of pregnant women attending SRH in ANC follow up 2019E.C .

\begin{tabular}{|l|l|l|}
\hline Dental visit & frequency & Percentage \\
\hline yes & 81 & 19.3 \\
\hline Tooth cleaning practice & frequency & Percentage \\
\hline Tooth brushing & 422 & 100 \\
\hline Tooth flossing & 81 & 19.3 \\
\hline Material used & frequency & Percentage \\
\hline Mefakya (traditional stick) & 319 & 75.5 \\
\hline Tooth brush with tooth paste & 103 & 24.5 \\
\hline
\end{tabular}

\section{DISCUSSION}

Assessment of the knowledge of the pregnant women regarding oral health care in our study revealed that $34.6 \%$ of the respondents have satisfactory knowledge. This is similar to the satisfactory knowledge that was reported from qassim province ,kingdom of Saudi Arabia which was $44.32 \%(26)$.And slightly lower than to the satisfactory knowledge that was reported from India which was 52.4\%(27).And much smaller than to the satisfactory knowledge that was reported from study done in Australia which was $78.5 \%$ (18).This difference is due to that awareness raising activities such as health information and health education for pregnant women regarding oral health care is not adequate. Regarding some of the oral health care knowledge components related to pregnancy, almost half of the respondents knew that tooth cleaning is more necessary during pregnancy. Around half of respondents knew that pregnant women may be susceptible to gingivitis but only $12.5 \%$ of them reported that gingivitis during pregnancy might lead to LBW and PTB which is comparable to the study conducted in Jimma Referral hospital ANC clinic attendant mothers which were 14\% (11). This indicates that the respondents have no enough knowledge about pregnancy associated oral cavity changes and adverse pregnancy out comes such as LBW and PTB.

In this finding the main change or problems related to mouth that were reported by women during pregnancy in SRH attending ANC clinic were bleeding gums which accounted $26 \%$ of the respondents. The result is similar to findings about bleeding gum from cross sectional study conducted in India which was $27.85 \%(12)$. Bleeding gum is normally one of the first signs of gingivitis and is common among pregnant women due to hormonal changes in this period which accentuate the gum's response to plaque. It is important to point out that pregnancy does not cause gingivitis, but may aggravate pre-existing disease (12).

In this finding concerning the practice of oral health care, $70.6 \%$ of the respondents were labeled to have "unsafe practice". This is similar with the percentage of unsafe practice that was reported in Saudi Arabia which was $66.88 \%$ (26).and much higher than the percentage of unsafe practice that was reported from cross sectional study conducted in India which was $44.5 \%(12)$ Specifically, In this finding only $19.3 \%$ of the respondents have visited dental practitioner during their pregnancy which was very much smaller than the study conducted on ANC clinic attendants in the UK regarding visiting dental practionaire which was $67 \%$ (8). In this study all respondents reported that they brush their teeth, and about one fourth of them reported the use of tooth brush with tooth paste. But, $74.9 \%$ of them brush their teeth once a day or irregularly. Only $12 \%$ of them brush their teeth twice a day which is contradicted with $87.6 \%$ which was reported from cross sectional study conducted in Australia (12).

\section{Conclusion}

Most of pregnant women (65.4\%) had unsatisfactory knowledge towards oral health care. Most of pregnant women (70.6) had unsafe practice towards oral health care.

\section{Recommendations}

The hospital administrators and other responsible bodies should make efforts to increase community based health education, awareness creation and improve better access to information for mothers regarding oral health care. Also participating the communities' stakeholders on planning, implementing, monitoring and evaluation is important to create sense of ownership. 
More research should also be carried out to explore more factors that hinder utilization of safe oral health care at the community level as well as the perspectives of the health care providers on how the services can be improved at the operational level in order to provide better guidelines for planners, administrators and policy maker.

\section{REFERENCES}

(1) Caufield PW, Yi L, \&Dasanayake A. Dental caries a transmissible and infectious disease. Compedium of continuing Education in Dentistry 2009; 26: 10-16.

(2) Michalowicz Bs, Hodges JS, DiAngelis AJ, Lupo VR, Novak MJ, \& Ferguson JE. Treatment of periodontal disease and the Risk of preterm birth. NEnglJMED 2009; 355(18): 1885-1894.

(3) Salvolini E, Giorgio R, Curatola A, Mazzanti L, Fratto G. Biochemical modification of human whole saliva induced by pregnancy. Br.JObstetGynaecol. 2011; 105(6): 656-60.

(4) Simplesteps.com. How Pregnancy Affects Your Oral Health. 2010. Retrieved from http://www.simplestepsdental.com/SS/ihtSSPrint/r.==/st.31848/t.35020/pr.3/c.359181.htmlon Jan 16, 2013.

(5). Ministry of Health. Good oral health for all, for life. The strategic vision for oral health in New Zealand. Wellington: Ministry of Health. 2012.

(6)RakchanokN, Amporn D, Yoshida Y, Rashid H, \& Sakamoto J. Dental caries and gingivitis among pregnant and non-pregnant women in Chiang Mai, Thailand. Nagoya J. Med. Sci. 2010; 72: 43-50.

(7)American Academy of Periodontology. Protecting oral health throughout your life. Women and gum diseaseAAP Oral Health Tips. 2008. Retrieved from http://perio.org./consumer/women.htm on Jan 15, 2013.

(8)Mills LW, Mosses DT: Oral health care during pregnancy. AmJ matern child Nurs 2012; 27(5) :275-280

(9) Thomas N, Middleton P, \& Crowther C. Oral and dental health care practices in pregnant women in Australia: a postnatal survey. Biomed Central Pregnancy and Childbirth 2011; 8(13): 1-6.

(10)Hullah E, Turok Y, Nauta M, and Yoong W. Self-reported oral hygience haits, dental attendance and attitudes to dentistry during pregnancy in a sample of immigrant women in North London. Arch Gynecol Obstet.

(11) Meron Y.(DMD). Knowledge and attitude towards oral health care in pregnant women attending ANC, clinic, Jimma, South-west Ethiopia, may 2010.(unpublished)

(12) Chai, W., \& Ngeow, W. (1998). Dental care for pregnant patients: a reappraisal. Annals of Dentistry University Malaya, 5

(13) Kelta E. (2012). Knowledge, attitude and practice towards oral health care among pregnant women attending Tarcha district hospital, Dawro zone, southern Ethiopia. (Unpublished).

(14) MDBV Piscoya, RAA Ximenes, GM Silva, SR Jamelli - Clinics, 2012 - SciELO Brasil

(15) Ethiopian Demograpic and Health Survey,2016

(16) WHO Antenatal Care Trial Research Group - The Lancet, 2001

(17)H Silk, AB Douglass, JM Douglas - American family, 2008 - ginecologo-ostetrica.i

(18) A George, M Johnson, A Blinkhor - Australian dental journal, 2013 - Wiley Online Library

(19) Gilbert A., \& Nuttall N. Self-reporting of periodontal health status. British Dental Journal 2010; 186(5): 241244.

(20) ) Laine M. (2002), Effect of pregnancy on periodontal and dental health. Acta Odontol Scand 2012; 60(5): 257-264

(21) Rateitschak K. Tooth mobility changes in pregnancy. Journal of Periodontal Research 2011; 2(3): 199-206.

(22) Rugg-Gunn A., \&Hackett A. (Eds.). Nutrition and Dental Health. New York: Oxford University Press 2010. p. 719

(24) ) Offenbacher S, Boggess K, Murtha A, Jared H, Lieff S, Mckaig R. Progressive periodontal disease and risk of very preterm delivery. Obstetrics and Gynecology 2009; 107(1): 29-36.

(25) Aushutosh Ni,TarunG,TegebirS ,Samir A and Ramandeep S, oral health knowledge and awareness among pregnant women in India ,Pub med central ,2015:19(6) :612-617.

(26) Nabilla Ahmed S,assessment of the knowledge ,perception,attitude and practice of expectant and lactating mothers regarding their own as well as their infants oral health in Qassim province ,kingdom of Saudi Arabia ,JP- journal 2016:6(1):26-32

(27) Ann T,Anoop J, Dhanalakshimi K, Prya S , and Soworya S ,evaluation the knowledge and attitude of expectant mothers about infant oral health status and their own oral hygiene ,Pub med cebntral $2015: 5(5) 400-405$

(28) A George, M Johnson, A Blinkhor - Australian dental journal, 2013 - Wiley Online Library 


\section{List of Tables}

Table 1:-socio demographic characteristics of pregnant women attending ANC at SRH 2019 e.c.

\begin{tabular}{|c|c|c|c|c|}
\hline & variables & catagories & frequency & percentage \\
\hline \multirow[t]{5}{*}{1} & \multirow[t]{5}{*}{ Age } & $15-19$ & 15 & 3.5 \\
\hline & & $20-24$ & 242 & 57.3 \\
\hline & & $25-29$ & 116 & 27.5 \\
\hline & & $30-34$ & 24 & 5.5 \\
\hline & & $35-39$ & 25 & 5.9 \\
\hline \multirow[t]{3}{*}{2} & \multirow[t]{3}{*}{ marital status } & married & 373 & 88.4 \\
\hline & & widowed & 5 & 1.2 \\
\hline & & single & 44 & 10.4 \\
\hline \multirow[t]{4}{*}{3} & \multirow[t]{4}{*}{ religion } & orthodox & 115 & 27.2 \\
\hline & & muslim & 192 & 45.4 \\
\hline & & protestant & 103 & 24.3 \\
\hline & & others & 12 & 3.2 \\
\hline \multirow[t]{4}{*}{4} & \multirow[t]{4}{*}{ ethnicity } & tigray & 57 & 13.6 \\
\hline & & oromo & 118 & 28 \\
\hline & & amhara & 87 & 20.5 \\
\hline & & others & 160 & 37.9 \\
\hline \multirow[t]{5}{*}{5} & \multirow[t]{5}{*}{ educational status } & illetrate & 61 & 14.5 \\
\hline & & primary & 82 & 19.4 \\
\hline & & secondary & 123 & 29.2 \\
\hline & & college & 123 & 29.2 \\
\hline & & higher education & 33 & 7.8 \\
\hline \multirow[t]{6}{*}{6} & \multirow[t]{6}{*}{ occupation } & housewife & 149 & 35.3 \\
\hline & & student & 26 & 6.2 \\
\hline & & merchant & 106 & 25.1 \\
\hline & & government employee & 67 & 15.9 \\
\hline & & private employe & 40 & 9.5 \\
\hline & & others & 34 & 8 \\
\hline \multirow[t]{3}{*}{7} & \multirow[t]{3}{*}{ income per month } & $<500$ birr & 140 & 33.2 \\
\hline & & 500-1000 birr & 197 & 46.8 \\
\hline & & $>1000$ birr & 85 & 19.9 \\
\hline \multirow[t]{2}{*}{8} & \multirow[t]{2}{*}{ residence } & rural & 299 & 70.9 \\
\hline & & urban & 123 & 29.1 \\
\hline
\end{tabular}

Table 2:-Knowledge of pregnant women attending SRH in ANC Follow up 2019 E.C.

\begin{tabular}{|l|l|l|l|}
\hline S.No & Statements of knowledge & Yes \\
\cline { 3 - 4 } & & No & $\%$ \\
\hline 1 & Tooth cleaning is more necessary during pregnancy & 188 & 44.5 \\
\hline 2 & Tooth should be cleaned at least twice a day & 133 & 31.5 \\
\hline 3 & Tooth should be cleaned using tooth brush with tooth paste for at least 2-3 minutes & 143 & 33.9 \\
\hline 4 & Not keeping oral hygiene can lead to gum and tooth disease & 162 & 38.3 \\
\hline 5 & Gum disease can cause bad oral breath & 171 & 40.6 \\
\hline 6 & Periodontitis could result in tooth loss & 196 & 46.4 \\
\hline 7 & Gingivitis during pregnancy could lead to LBW and PTB & 53 & 12.5 \\
\hline 8 & Pregnant women may be susceptible to gingivitis & 140 & 33.1 \\
\hline 9 & Gingivitis can cause red, swollen gums that will bleed easily & 133 & 31.5 \\
\hline 10 & Gingivitis can be treated with careful brushing and flossing at home & 138 & 32.8 \\
\hline
\end{tabular}


Table 3:- Tooth cleaning practice and material used for tooth cleaning practiceduring pregnancy of pregnant women attending SRH in ANC follow up 2019E.C .

\begin{tabular}{|l|l|l|}
\hline Dental visit & frequency & Percentage \\
\hline yes & 81 & 19.3 \\
\hline Tooth cleaning practice & frequency & Percentage \\
\hline Tooth brushing & 422 & 100 \\
\hline Tooth flossing & 81 & 19.3 \\
\hline Material used & frequency & Percentage \\
\hline Mefakya (traditional stick) & 319 & 75.5 \\
\hline Tooth brush with tooth paste & 103 & 24.5 \\
\hline
\end{tabular}

